\title{
面発光レーザーの最近の進展一高速変調と機能集積一
}

\author{
小山二三夫 \\ 東京工業大学 精密工学研究所 ( $=226-8503$ 神奈川県横浜市緑区長津田町4259-R2-22)
}

\section{Recent Progress of Surface Emitting Lasers \\ - High-Speed Modulation and New Functions -}

\author{
Fumio KOYAMA \\ RP\&I Lab., Tokyo Institute of Technology, 4259-R2-22 Nagatsuta, Midori-ku, Yokohama, Kanagawa 226-8503
}

(Received April 18, 2015)

\begin{abstract}
A vertical cavity surface emitting laser (VCSEL) was born in Japan. The 38 years' research and developments opened up various applications including datacom, sensors, optical interconnects, spectroscopy, optical storages, printers, laser displays, laser radar, atomic clock and high power sources. A lot of unique features have been already proven, such as low power consumption, a wafer level testing and so on. The market of VCSELs has been growing up rapidly and they are now key devices in local area networks, and optical interconnections in data centers and supercomputers. In this paper, the advances on VCSEL photonics will be reviewed. We present the high-speed modulation of VCSELs based on a coupled cavity structure. For further increase in transmission capacity per fiber, the wavelength engineering of VCSEL arrays is discussed, which includes the wavelength stabilization and wavelength tuning based on a micro-machined cantilever structure. We also address a lateral integration platform and new functions, including high-resolution beam scanner, vortex beam creation and largeport free space wavelength selective switch with a Bragg reflector waveguide.
\end{abstract}

Key Words: Vertical cavity surface emitting lasers, Optical interconnects, Data center, Tunable semiconductor lasers

\section{1. はじめに}

面発光レーザー (Vertical Cavity Surface Emitting Laser: VCSEL) は, 伊賀 健一元東京工業大学学長の発明から 38 年を迎えた ${ }^{1-4)}$. 低しきい值電流化が進められ, 消費電 力が小さい, 2次元アレー化が可能, ウェ八単位での性 能試験が可能であるなど, 従来構造の半導体レーザーに 比べて多くの利点が実証されてきた ${ }^{5-13)}$ 。 世界中で精力 的に研究開発が進められ，これまでの研究開発により， レーザー単体としての性能も通常の半導体レーザーを大 きく凌ぐようになってきた。サブミリアンペアの低しき い值素子の実現や近赤外波長域での実用化が進められ て, 現在の短距離光LANやデータセンター・スーパー コンピュータ内の光インターコネクト用光源として中心 的な役割を果たしている。さらに，Fig.1に示すように， レーザーマウス, 高精細高速カラープリンタに搭載さ れ, また医用応用の光源としての研究開発も進められて いる．以前では想像もできなかったような応用面での実 用化が進められている。特に，スーパーコンピュータや データセンターでは, 膨大な数の光配線導入が必須であ り, ここでは, 低消費電力動作を可能とする面発光レー
ザーが主役になっている. $40 \mathrm{Gbps}$ を越える高速直接変 調動作， 1 bit当たりの消費電力として $100 \mathrm{fJ}$ 以下どの 低消費電力動作など, 将来の低消費電力インターコネク トのための革新的な開発が進められている ${ }^{14-18)}$ 。さら に，民生応用でも，高精細映像伝送システムに搭載され るなど，実用化面でも大きな進展が見られる，発光波長 域も, 最近では青色, 緑色, 赤色の可視光域から, 現在 データリンク・インターコネクトで主流の $850 \mathrm{~nm}$ 帯,

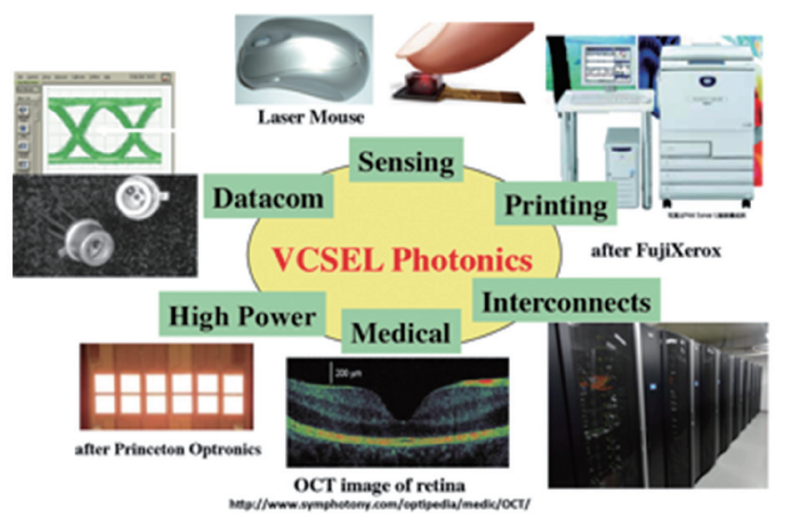

Fig. 1 Applications of VCSEL photonics. 
高信頼化 ·高速化を目指した1060 nm带, 光アクセス用 $1300 \mathrm{~nm}-1550 \mathrm{~nm}$ 帯, センサー応用として1500 nm〜 $2000 \mathrm{~nm}$ 帯の長波長帯面発光レーザーなど, 広範囲の波 長域での研究開発が進められている ${ }^{19-30)}$.

機能面では，MEMSとの融合による広帯域での連続波 長掃引技術 ${ }^{31-33)}$ は, OCT (Optical Coherence Tomography) などの生体観測用途で大きな注目を浴びている ${ }^{34)}$. $100 \mathrm{~nm}$ にぶ広帯域連続波長掃引は, 面発光レーザー 構造でなければ実現が困難である。また, 微小共振器の 特徵を活かすことで, 温度変化に対して絶対波長を安定 化したアサーマル半導体レーザーや, 高密度な多波長集 積化技術など，面発光レーザー固有の優れた特性も実証 されている ${ }^{35-39)}$ ，さらに，面発光レーザーを形成する多 層膜反射鏡構造を用いたスローライト伝搬を活用するこ とで, 数十 $\mu \mathrm{m}$ の超小型の光スイッチ, 光変調器, 光増 幅器, ビーム偏向器の新機能素子の提案・実証も行わ れ，これらの機能デバイスは，面発光レーザーとの集積 化も実証されている ${ }^{40-44)}$. また，これまで面発光レー ザーは低消費電力特性を活かした低パワー応用が主で あったが, アレー化による高出力励起光源, ビーム形状 制御による高出力動作など，パワーデバイスへの展開も 見られる ${ }^{45}$.

本論文では，面発光レーザーを基盤とした面発光レー ザーフォトニクスともいうべきフォトニクス技術の最近 の進展について述べる。

\section{2. 面発光レーザーの高速化}

スパコンやデータセンターの装置間・装置内における 光インターコネクトへの適用が急速に進められており, 近い将来 $100 \mathrm{Gbps}$ 超の高速化のニーズは大きいものの, 現状技術は10 Gbpsの伝送速度に留まっている. 実験室 レベルでは, $40 \mathrm{Gbps}$ 動作が報告されているものの ${ }^{46)}$, 動作条件を加味した実用レベルでは25 Gbpsが限界と見 られている。 また, 電気段での補償回路による64 Gbps 変調の報告もあるものの ${ }^{47)}$, 電気回路による付加的な消 費電力が伴う. 面発光レーザーの高速化については, 結 合共振器の差動変調, 外部光変調器積層集積, 光注入同 期などの方法が高速化のために検討されたが ${ }^{48-50)}$, 変調 帯域の限界や安定性などで課題が多い.

筆者らは，Fig. 2とFig. 3に示すように，面発光レー ザーに微小共振器を横方向に集積することで, 光学的な フィードバックにより変調帯域を 3 倍程度まで拡大でき ることを見出した ${ }^{42,51,52)}$. 結合共振器における複数の モード間のビートより変調感度の高周波数側が増大する ためである ${ }^{51)}$ ，基盤となるデバイス構造は通常の $980 \mathrm{~nm}$ 帯面発光レーザーと同一であり, 大幅な高速化が可能に なっている。比較のために図中に示した通常の面発光 レーザーでは，変調速度は，光と電子の相互作用による 緩和振動周波数と素子の浮遊容量による帯域制限で律速 される。この手法の特色は, レーザー共振器とは別に新 たな共振器を集積することで光帰還により, その変調特 性を光学的に制御するものであり, 材料などの特性で律

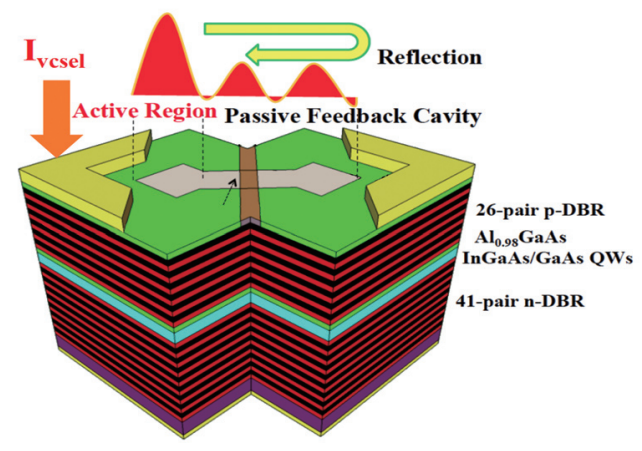

Fig. 2 Schematic structure of the transverse coupledcavity VCSEL. ${ }^{51}$

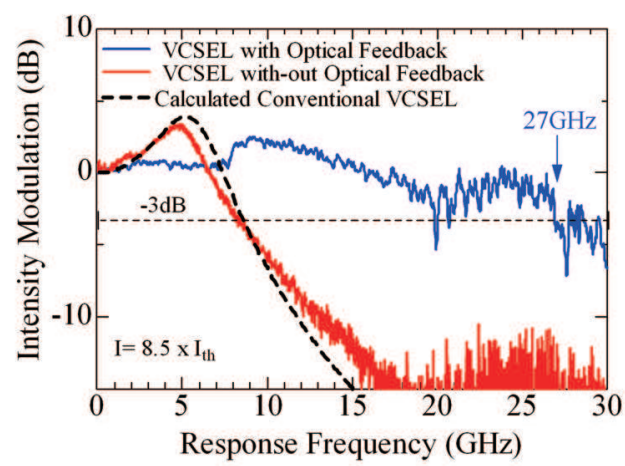

Fig. 3 Measured small-signal modulation response of transverse coupled cavity VCSEL with and without optical feedback. ${ }^{52)}$

速される速度限界を打破できる。精密に結合共振器を制 御することで, 緩和振動周波数の限界打破に留まらず, 浮遊容量による帯域律速をも補償できることが実験的に も示唆されている。この方法は, 端面発光型レーザーで も変調帯域の拡大のために検討され40 Gbpsの直接変調 が報告されたが，縦モードを安定に制御する必要があっ た。本手法は，前述した横方向伝搬のスローライトを使 うことで帯域改善のための結合共振器のサイズを大幅に 小型化が可能であり安定な動作が期待できる ${ }^{53)}$.

上記の結合共振器では, 面発光レーザー共振器から レーザー出力とは直交する横方向に光が結合する。この 横方向に伝搬する光の群速度は, 固体中の通常の伝搬光 に比べて，約 $1 / 50$ 以下まで減速した光，すなわちスロー ライトであることがわかっている，スローライトの効果 により, 一方の共振器に $1 \mathrm{~V}$ 以下の微小信号電圧を印加 して，サブ10 $\mu \mathrm{m} の$ 小さな素子長の超小型光変調器が実 現できる。これらの研究は，100 Gbps級の高速変調を可 能にする超高速面発光レーザー光源を可能にする．加速 する電子機器間 · 内における光配線の高速化・高密度配 線化・低消費電力化を可能とするキイデバイスになると 期待される。

製作した変調器集積VCSELの構造図と小信号変調特 性をFig. 4 とFig. 5に示す ${ }^{54)}$ 。 上部DBR，下部DBRはそれぞ れAlGaAs DBR 25ペア，40ペア，活性層は $\operatorname{In}_{0.2} \mathrm{Ga}_{0.8} \mathrm{As} / \mathrm{GaAs}$ の3重量子井戸からなる。横方向に伝搬する光の群速度 を制御して素子長 $30 \mu \mathrm{m}$ 程度の超小型高速光変調器集積 光源の可能性を示している. 変調帯域は, 素子の浮遊容 


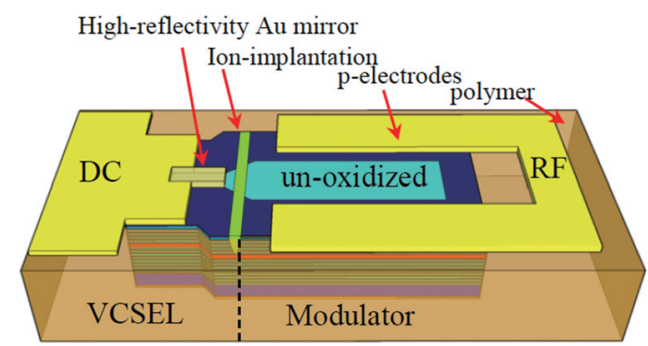

Fig. 4 Schematic structure of the slow-light modulator laterally integrated with VCSEL. ${ }^{54}$

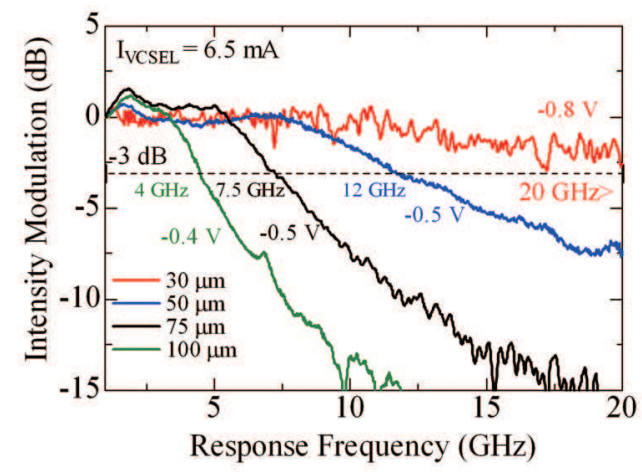

Fig. 5 Measured small-signal modulation response of the modulator integrated VCSEL with different bias voltage from 0.8 to $0.4 \mathrm{~V}$ for the modulator lengths of 30 to $100 \mu \mathrm{m} .^{54}$

量で律速されている，更なる小型化でより高速の変調が 期待できる ${ }^{55)}$. 変調電圧 $400 \mathrm{mV}_{\mathrm{pp}}$ 以下で消光比 $5 \mathrm{~dB}$ 以上 の低電圧動作を実証するとともに，25 Gbpsまでの高速 変調動作を実現し, 低消費電力動作と高速化の両立の可 能性を示している.

\section{3. 波長集積・制御技術}

大容量の波長分割多重(WDM)や波長ルーティング機 能を活用した光波ネットワークでは, 波長可変レー ザー, 可変光フィルタなどの可変機能を有するデバイス が鍵となる. 光マイクロマシンにおける機械的な微小変 位を活用することで, 従来の固体中の屈折率変化を用い た波長可変デバイスの性能を大きく凌駕することが期待 できる ${ }^{31)}$ 。例えば，DFBレーザーやDBRレーザーを基本 とした波長可変レーザーでは，連続的に掃引可能な波長 幅の制限や，モード跳躍などが課題である。基板と垂直 に共振器を形成する面発光レーザーは, 共振器の長さが 波長の数倍の微小共振器であるため, 完全な単一縦モー ド動作が可能であり，マイクロマシン技術を取り入れる ことで，大きな連続的な波長掃引幅を可能とする波長可 変レーザーへの応用が注目されている。薄膜半導体での 横方向周期構造であるサブ波長回折格子を使ったマイク ロマシン面発光レーザーでは, 低電圧駆動でのMHz領 域までの高速波長掃引も実現されている56,57)

一方，筆者らはこれまで薄膜中の熱応力を利用するこ とで, 波長温度係数が, 通常の単一モードレーザーの約 $1 / 50$ 以下という温度無依存の光共振器や波長可変レー
ザーハイルタが可能であることを実証している

Fig. 6はGaAs系のMEMS構造を集積した波長温度無依存 の面発光レーザーの電子顕微鏡写真である。波長温度係 数を通常の単一モードレーザーの1/10に抑圧しながら， 約10 nmに渡って連続波長掃引が可能になるなど，ア サーマル波長可変半導体レーザーが実現されている。イ ンターコネクトに限らず，WDMを用いたアクセスネッ トワーク用光源としても注目されている ${ }^{58)}$.

\section{4. 新機能集積}

VCSELから横方向に光を伝搬させると，巨大な構造 分散によりスローライト伝搬や，巨大角度分散素子， ビーム偏向素子, Vortexビーム形成など，新しい機能を 集積することができる。著者らはVCSEL構造であるブ ラッグ反射鏡 (DBR) 導波路を用いて超高解像度ビーム 掃引を実現してきた ${ }^{59-61)}$ 。非機械式のビーム偏向として は，これまでで最高の解像点数1,000を越える高解像度1 次元ビーム掃引を実現している。ささらこの構造では, ブラッグ反射鏡導波路のレイアウトを2次元的に変更す ることによって, Vortexビーム生成が可能である。リン グ状導波路に沿って位相遅れを伴いながら上部へ放射す るため, Vortexビーム固有のスパイラル状の波面が形成 される ${ }^{62)}$. Vortexビームは, 軌道角運動量 $(\mathrm{OAM})$ を有し ており，ドーナッ状の強度分布を示す。近年, この OAMビームはモード多重光通信や量子情報への応用で 注目されている ${ }^{63)}$. Fig. 7とFig. 8は, 面発光レーザーと の集積光源のデバイス構造と遠視野像/近視野像を示し ている ${ }^{64)}$.リング状導波路に沿って伝搬し，波面の傾斜 を伴って光が放射される様子が観測される。数十ミクロ ンの小型のVortex光源が実現可能である。

波長感度に優れたビーム掃引デバイスをアレー状に高 密度に集積し, 液晶空間変調器からなる空間光学系を用

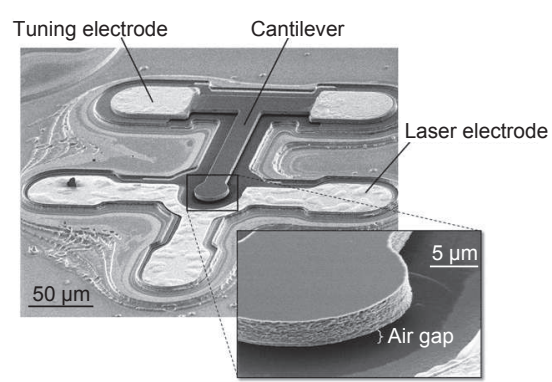

Fig. 6 SEM view of the athermal and tunable MEMS VCSEL. ${ }^{37)}$

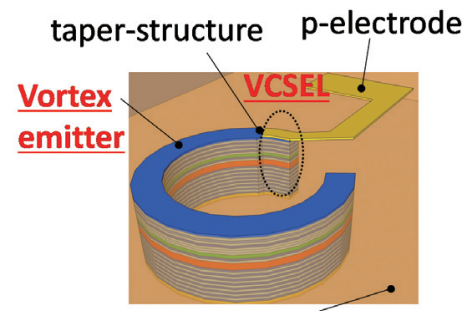

Fig. 7 Vortex beam emitter integrated with VCSEL. ${ }^{64)}$ 
(a)

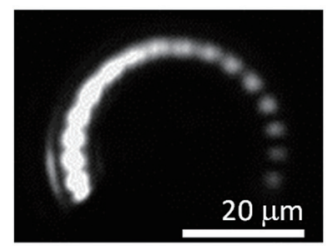

(b)

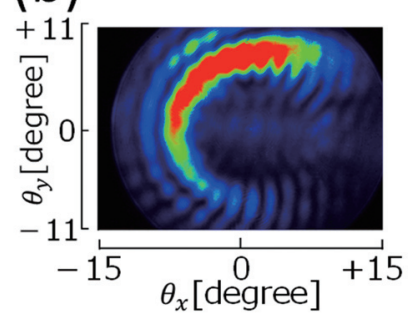

Fig. 8 (a) Measured near field patterns (NFP) and (b) far field patterns (FFP) from ring-shaped beam generated vortex beam emitter. ${ }^{64)}$

いて，従来技術より出力ポート数が大幅に大きな 200 ポートを搭載可能な波長選択スイッチへの展開も報告さ れている ${ }^{65,66)}$ 。この巨大な角度波長分散素子は, さらに 高密度のアレー化も可能であり, 自由空間光学系との組 み合わせによるスケーラビリティの優れた大規模波長数 に対応する超小型光合分波器 · 波長選択スイッチへの展 開が示唆されている67).

\section{5. 結 論}

面発光レーザーは, 38年の研究開発を経て, デー夕通 信, 光センサなどで大きく花開き, さらに今後は, 数億 個規模の超高速大容量光インターコネクト, 大容量光ア クセス, 様々なセンシング応用, 医療応用, レーザー加 工，など多様な分野への浸透が期待できる，応用分野の 広がりとともに，さらなる新技術の創出を期待したい。

\section{謝 辞}

日頃からご指導頂く末松安晴栄誉教授, 伊賀 健一名 誉教授に感謝する。ここで紹介した研究の一部は, 科研

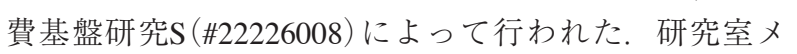
ンバー各位の協力に深く感謝する.

\section{参考文献}

1) K. Iga: IEEE J. Sel. Top. Quantum Electron. 6 (2000) 1201.

2) K. Iga: Jpn. J. Appl. Phys. 47 (2008) 1.

3) F. Koyama: Journal of Lightwave Technology 24 (2006) 4502.

4) H. Soda, K. Iga, C. Kitahara, and Y. Suematsu: Jpn. J. Appl. Phys. 18 (1979) 2329.

5) K. Iga, S. Kinoshita, and F. Koyama: Electron. Lett. 23 (1987) 134.

6) F. Koyama, S. Kinoshita, and K. Iga: Appl. Phys. Lett. 55 (1989) 221.

7) J. L. Jewell, A. Scherer, S. L. McCall, Y. H. Lee, S. Walker, J. P. Harbison, and L. T. Florez: Electron. Lett. 25 (1989) 1123.

8) R. S. Geels, S.W. Corzine, and L. A. Coldren: IEEE J. Quantum Electron. 27 (1991) 1359.

9) D. L. Huffaker, D. G. Deppe, K. Kumar, and T. J. Rogers: Appl. Phys. Lett. 65 (1994) 97.

10) K. D. Choquette, K. M. Geib, C.I.H. Ashby, C. I. H. Twesten, R. D. Blum, H. Q. Hou, D. M. Follstaedt, B. E. Hammons, D. Mathes, and R. Hull: IEEE J. Sel. Top. Quantum Electron. 3 (1997) 916.

11) Y. Hayashi, T. Mukaihara, N. Hatori, N. Ohnoki, A. Matsutani, F. Koyama, and K. Iga: IEEE Photon. Technol. Lett. 7 (1995) 1234.

12) K. L. Lear, K. D. Choquette, R. P. Schneider, Jr., S. P. Kilcoyne,

and K. M. Geib: Electron. Lett. 31 (1995) 208.

13) R. Jäger, M. Grabherr, C. Jung, R. Michalzik, G. Reiner, B.Wigl, and K. J. Ebeling: Electron. Lett. 33 (1997) 330.

14) A. Larsson: IEEE J. Sel. Top. Quantum Electron. 17 (2011) 1552.

15) P. K. Pepeljugoski, J. A. Kash, F. Doany, D. Kuchta, L. Schares, C. Schow, M. Taubenblatt, B. J. Offrein, and A. Benner: Optical Fiber Communication Conference paper OThX2 (2012).

16) A. Mutig, S. A. Blokhin, A. M. Nadtochiy, G. Fiol, J. A. Lott, V. A. Shchukin, N. N. Ledentsov, and D. Bimberg: Appl. Phys. Lett. 95 (2009) 131101.

17) N. Suzuki, T. Anan, H. Hatakeyama, K. Fukatsu, K. Yshiki, K. Tokutome, T. Akagawa, and M. Tsuji: IEICE Trans. Electron. E92-C (2009) 942.

18) P. Westbergh, R. Safaisini, E. Haglund, B. Kogel, J. S. Gustavsson, A. Larsson, M. Geen, R. Lawrence, and A. Joel: Electron. Lett. 48 (2012) 1145.

19) T. Baba, Y. Yogo, K. Suzuki, F. Koyama, and K. Iga: Electron. Lett. 29 (1993) 913.

20) N. Nishiyama, M. Arai, S. Shinada, M. Azuchi, T. Miyamoto, F. Koyama, and K. Iga: IEEE J. Sel. Top. Quantum Electron. 7 (2001) 242.

21) J. A. Lott, N. N. Ledentsov, V. M. Ustinov, N. A. Maleev, A. E. Zhukov, A. R. Kovsh, M. V. Maximov, B. V. Volovik, Zh. I. Alferov, and D. Bimberg: Electron. Lett. 36 (2000) 1384.

22) K. D. Choquette, J. F. Klem, A. J. Fischer, O. Blum, A. A. Allerman, I. J. Fritz, S. R. Kurtz, W. G. Breiland, R. Sieg, K. M. Geib, J. W. Scott, and R. L. Naone: Electron. Lett. 36 (2000)1388.

23) A. Karim, P. Abraham, D. 1 Lofgreen, Y.-J. Chiu, J. Piprek, and J. Bowers: Appl. Phys. Lett. 78 (2001) 2632.

24) M. Ortsiefer, S. Baydar, K. Windhorn, E. Ronneberg, J. Rosskopf, R. Shau, M. Grau, G. M.Bohm, and M.-C Amann: Electron. Lett. 41 (2005) 807.

25) N. Nishiyama, C. Caneau, B. Hall, G. Guryanov, M. Hu, X. Liu, M. J. Li, R. Bhat, and C.-E. Zah: IEEE J. Sel. Top. Quantum Electron. 11 (2005) 990.

26) V. Iakovlev, G. Suruceanu, A. Caliman, A. Mereuta, A. Mircea, C.-A.Berseth, A. Syrbu, A. Rudra, and E. Kapon: Photon. Technol. Lett. 17 (2005) 947.

27) W. Hofmann, N.H.Zhu,, M. Ortsiefer,G, Bohm, J. Rosskopf, L. Chao, S. Zhang, M. Maute, and M.-C Amann: Photon. Technol. Lett. 18 (2006) 424.

28) T. C. Lu, S. W. Chen, T. T. Wu, P. M. Tu, C. K. Chen, C. H. Chen, Z. Y. Li, H. C. Kuo, and S. C. Wang: Appl. Phys. Lett. 97 (2010) 071114 .

29) K. Johnson, M. Hibbs-Brenner, W. Hogan, and M. Dummer: Advances in Opt. Technol. 2012 (2012) 569379.

30) C. L. Felix, W. W. Bewley, I. Vurgaftman, J. R. Meyer, L. Goldberg, D. H. Chow, and E. Selvig: Appl. Phys. Lett. 71 (1997) 3483.

31) C. J. Chang-Hasnain: IEEE Sel. Top. Quantum Electron. 6 (2000) 978.

32) M. C. Larson, B. Pezeshki, and J. S. Harris: IEEE Photon. Technol. Lett. 7 (1995) 382.

33) M. Maute, B. Kogel, G. Bohm, P. Meissner, M.-C.Amann: IEEE Photon. Technol. Lett. 18 (2006) 688.

34) I. Grulkowski, J. J. Liu, B. Potsaid, V. Jayaraman, C. D. Lu, J. Jiang, A. E. Cable, J. S. Duker, and J. G. Fujimoto: Biomedical Opt. Express 3 (2012) 2733.

35) W. Janto, K. Hasebe, N. Nishiyama, C. Caneau, T. Sakaguchi, A. Matsutani, P. Babu Dayal, F. Koyama, and C. E. Zah: IEEE International Semiconductor Laser Conference, PD1.1, Hawaii (2006).

36) H. Sano, A.Matsutani, and F. Koyama: Appl. Phys. Express 2 (2009) 072101.

37) M. Nakahama, T. Sakaguchi, A. Matustani, and F. Koyama: Opt. Express 22 (2014) 21471.

38) M. Nakahama, H. Sano, S. Inoue, T. Sakaguchi, A. Matsutani, and F. Koyama: IEEE Photon. Technol. Lett. 25 (2013) 1747.

39) M. Nakahama, T. Sakaguchi, A. Matsutani, and F. Koyama: Appl. Phys. Lett. 105 (2014) 091110.

40) G. Hirano, F. Koyama, K. Hasebe, T. Sakaguchi, N. Nishiyama, C. Caneau, and C-E. Zah: Optical Fiber Communications Conference, PDP34, Anaheim, California, 25-29 (2007).

41) A. Fuchida, A. Matsutani, and F. Koyama: Opt. Lett. 36 (2011) 2644. 
42) H. Dalir and F. Koyama: IEICE Electronics Express 8 (2011) 1075.

43) T. Shimada, A. Matsutani, and F. Koyama: Appl. Opt. 53 (2014) 1766.

44) H. Dalir, Y.Takahashi, and F. Koyama: Electron. Lett. 50 (2014) 101.

45) J. F. Seurin, G. Xu, V. Khalfin, A. Miglo, J.D. Wynn, P. Pradhan, C. L. Ghosh, and L.A. D'Asaro: Proc. SPIE 7229 (2009) 722903.

46) A. Larsson, C. Carlsson, J. Gustavsson, A. Haglund, P.Modh, and J. Bengtsson: New J. Phys. 6 (2004) 176.

47) D. M. Kuchta, A. V. Rylyakov, C. L. Schow, J. E. Proesel, C. Baks, P. Westbergh, J. S. Gustavsson, and A. Larsson: Optical Fiber Communication Conference, Th3C.2 (2014).

48) C. Chen and K. D. Choquette: IEEE J. Lightwave Technol. 28 (2010) 1003.

49) T. D. Germann, W. Hofmann, A. M. Nadtochiy, J. Schulze, A. Mutig, A. Strittmatter, and D. Bimberg: Opt. Express 20 (2012) 5099.

50) X. Zhao, Y. Zhou, C. J. Chang-Hasnain, W. Hofmann, and M. C. Amann: Opt. Express 14 (2006) 10500.

51) H. Dalir and F. Koyama: Appl. Phys. Lett. 103 (2013) 091109.

52) H. Dalir and F. Koyama: Appl. Phys. Express 7 (2014).

53) H. Dalir and F. Koyama: Electron. Lett. 50 (2014) 823.

54) H. Dalir, Y. Takahashi, and F. Koyama: Opt. Express 22 (2014) 25746.

55) H. Dalir and F. Koyama: Appl. Phys. Express 7 (2014) 112101
56) M. C.Y. Huang, Y. Zhou, and C. J. Chang-Hasnain: Nature Photon. 2 (2008) 180

57) C. J. Chang-Hasnain, Y. Zhou, M. C. Y. Huang, and C. Chase: IEEE J. Sel. Top. Quantum Electron. 15 (2009) 869.

58) F. Koyama: Optical Fiber Communication Conference, W1J.4 (2015).

59) X. Gu, T. Shimada, and F. Koyama: Opt. Express 19 (2011) 22675.

60) X. Gu, T. Shimada, A. Matsutani, and F. Koyama: IEEE Photonics Journal 4 (2012) 1712.

61) F. Koyama and X. Gu: IEEE J. Sel. Top. Quantum Electron. 19 (2013) 1701510

62) S. Mochizuki, X. Gu, K.Tanabe, A. Matsutani, M. Ahmed, A. Bakry, and F. Koyama: Appl. Phys. Express 7 (2014) 022502.

63) L. Allen, M. W. Beijersbergen, R. J. C. Spreeuw, and J. P. Woerdman: Phys. Rev. A 45 (1992) 8185

64) K. Tanabe, X. Gu, A. Matsutani, and F. Koyama: CLEO 2015 , SW1F.2 (2015).

65) X. Gu, and F. Koyama: Optical Fiber Communication Conference (2014) Th3F.1.

66) X. Gu, K. Seno, H. Tanobe, and F. Koyama: European Conference on Optical Fiber Communications (2014) We.3.5.3.

67) X. Gu, K. Suzuki, Y. Ikuma, K. Seno, H. Tanobe, A. Matsutani, and F. Koyama: J. Lightwave Technology 33 (2015) 1358.

\section{レーザーワード}

vortexビーム (vortex beam)

通常のガウスビームの波面が平面や曲率を持った曲面 であるのに対して，等位相面である波面が螺旋状になっ ている，伝播軸上では電界が打ち消しあって, 強度がゼ ロになり，ドーナツ形状の強度分布を有する。通常のガ ウスビームをらせん状位相プレートやコンピュータホロ グラムを通過・反射させることで生成することができ
る.ビーム断面内に軌道角運動量が発生し, 角運動量と いう新規のパラメータを持つ光波として, 加工, 光ピン セット，大容量空間多重通信など，その様々な応用に注 目が集まっている。

(小山二三夫) 